\title{
Gestão governamental e sociedade: informação, tecnologia e produção científica
}

\author{
Government management and society: \\ information, technology and scientific output
}

Patrícia Ribeiro ${ }^{1}$

Daniela Carvalho Sophia ${ }^{2}$

Deise deAraújo Grigório ${ }^{3}$

${ }^{1}$ Departamento de Ciências Sociais, Escola Nacional de SaúdePública, Fundação Oswaldo Cruz. Rua Leopoldo Bulhões 1480/90 andar, M anguinhos. 21041210 Rio deJaneiro RJ. patriciatr@ensp.fiocruz.br Escola de Governo em Saúde, Escola Nacional de SaúdePública, Fundação Oswaldo Cruz

${ }^{3}$ Centro deInformação Científica eTecnológica, Fundação Oswaldo Cruz
Abstract The complexity of government tasks today suggests that virtual interaction processes that could streamline flows and exchanges of information between governments and society in public policymaking may contribute to more effective intervention that is more closely attuned to the heterogeneity and diversity of social problems. Innovative participatory government administration initiatives have proliferated, together with the extension of public control over government actions, handled through by information technologies. Exploring this field, this paper identifies some key issues for better demarcation and qualification of such initiatives in public sector management, based on the authors' own experience in leading an institutional project designed to empower the political, technical, and communicative participation of society in discussions of the implementation of the Unified $\mathrm{N}$ ational $\mathrm{H}$ ealth System in Brazil. Based on a review of the literature analyzing the links among information, technology, development, and democracy, and particularly with regard to social management, this paper systematizesaspects for consideration drawn from in experiences of interactions between government and society, mediated by scientific knowledge, fostering greater transparency and plurality of views in government management.

Key words Democracy, Policy-making, Healthcare policy, Information science
Resumo A complexidadedastarefasgovernamentais na atualidade sugere que processos de interação virtual, capazes de agilizar a circulação e troca de informações entre governos e sociedade nos espaços de produção de políticas públicas, podem contribuir para intervenções mais resolutivas e sintonizadas com a heterogeneidade e diversidade dos problemas sociais. Proliferam iniciativas inovadoras de gestão governamental participativa e de extensão do controle público sobre as ações dos governos, mediadas pelas tecnol ogias de informação. 0 artigo examina este campo temático, identificando questões para a melhor delimitação e qualificação de iniciativas desta natureza nos espaços de gestão estatal, à luz da experiência das autoras na condução de um projeto institucional orientado a potenciar política, técnica e comunicativamente a participação da sociedade no debate sobre a implementação do Sistema Ú nico de Saúde. A partir de literatura sobre as relações entreinformação, tecnologia, desenvolvimento e democracia, especialmente no campo da gestão social, examina aspectos a considerar para que experiências de interatividade entre governo e sociedade, mediadas pelo conhecimento científico, contribuam para mais transparência epluralidade de visões na gestão governamental.

Palavras-chave Democracia, Formulação de políticas, Política de saúde, Ciência da informação 


\section{Introdução}

A literatura recentequeexamina as relações entre política, informação e comunicação social vem afirmando a importância da associação entre conhecimento e tecnologia: i) na produção de evidências para a construção e avaliação social de políticas públicas; ii) no fortalecimento das relações entre sociedade civil ePoder Público para a expansão da participação política nas decisões deinteressepúblico/coletivo; eiii) no desenvolvimento de inovações voltadas para a eficiência da gestão governamental e transparência do setor público.

No plano da ação governamental, dissemina-se a idéia de que nestes tempos de globalização, descentralização e inovação tecnológica, os crescentes desafios que se apresentam cotidianamente aos governantes na gestão das políticas públicas exigem respostas atualizadas com as novas dinâmicas do mundo virtual em expansão e com a heterogeneidade e diversidade do mundo real amplificado pela tecnologia.

A complexidade adquirida pelas tarefas governamentais está a indicar que processos de interação virtual, capazes de agilizar a circulação e troca de informações entre governos e sociedade nos espaços de produção de políticas públicas, em muito contribuiriam para o desenvolvimento de propostas e projetos de intervenção mais resolutivos e sintonizados com os variados problemas e necessidades locais, regionais e nacionais. Assim, multiplicam-se experiências de governo el etrônico, ou que visam ampliar a democracia el etrônica, testando novas formas de acesso público da sociedadea informações, intervenções e decisões governamentais.

Estudos que analisam iniciativas desta natureza identificam dificuldades importantes para sua consolidação no âmbito da administração pública tradicional, em virtude do padrão tecnológico exigido para o seu desenvolvimento, do perfil multifacetado do profissional e das equipes requisitados para seu gerenciamento e execução, de resistências culturais à interação virtual em processos políticos e de barreiras socioeconômicas no acesso aos meios necessários à inclusão digital.

Estas restrições, entretanto, não diminuem o potencial das novas tecnologias em estabelecer canais produtivos para a veiculação de informações, conhecimento e análises entre profissionais de instituições de ensino e pesquisa, executivos governamentais esociedade, como apoio a experiências inovadoras de cooperação técnica hori- zontal e vertical ou de gestão participativa de políticas setoriais.

No Brasil, no que se refere à gestão governamental da área da saúde, pode-se afirmar que, considerando as dimensões do território nacional, a diversidade local e regional, as desigualdades existentes entreos entes federados, o crescente fortalecimento da democracia e as abrangentes mudanças introduzidas pelo processo de descentralização, projetos de inovação científico-tecnológica no campo de interfaces entre conhecimento, tecnologia, ação governamental e sociedade podem representar um recurso importante para a qualificação da gestão descentralizada do Sistema Único de Saúde - SUS. Especialmentena produção de respostas mais eficazes aos problemas que afetam a população.

Este artigo realiza um primeiro percurso exploratório neste novo, porém vasto, campo temático, com o objetivo de sistematizar al gumas questões a serem aprofundadas por aqueles que trabalham em iniciativas desta natureza nos espaços de gestão estatal, à luz da experiência das autoras na condução de um projeto institucional que busca contribuir para potenciar política, técnica e comunicativamente a participação da sociedade no debate setorial sobre a implementação do SUS e de sua gestão descentralizada.

\section{Informação, tecnologia, desenvolvimento e democracia}

A ampla disseminação mundial das novas tecnologias de informação e a crescente percepção de seu valor político nas experiências internacionais de democratização da intervenção estatal concorreram, nas últimas duas décadas, para um tempo de experimentação deinovações sem igual no estabelecimento de iniciativas de gestão governamental participativa e de extensão do controle público sobre as ações do governo.

No âmbito da literatura sobre gestão social, a democratização da informação vem sendo valorizada como chave para um desenvolvimento político que fortaleça práticas de planejamento e avaliação participativas. Avalia-se que naquelas sociedades onde a esfera pública tem peso no desenvolvimento político, a informação - que tematize a vida política e institucional - contribui paraqueorganizações, funcionáriose demaisatores melhorem seu desempenho em suas tarefas de transformar direitos em realidade. Contribui, igualmente, para que relatórios técnicos orientados ao aperfeiçoamento de projetos e programas 
governamentais se convertam em um processo de prestação de contas a cidadãos que viabilize o controle político do investimento social ${ }^{1}$.

Considera-se ainda que a necessidade de se construir amplos consensos técnicos e políticos em instâncias de decisão compartilhada é um desafio contemporâneo que os planejadores não podem evitar. Observa-se internacionalmente uma ten dência à valoração da obtenção de consensos e à instituição de processos de decisão governamental baseados em decisões unânimes, em diferentes sistemas políticos ${ }^{2,3}$. N estecontexto, a produção esocialização de informação, vinculadas ao alargamento dos espaços de discussão pública, são identificadas como insumosfundamentais para ações institucionais orientadas à constituição de processos de planificação social democráticos ${ }^{1}$.

No âmbito do debate internacional sobre o desenvolvimento social, advoga-se que a instalação de sistemas que permitam o acompanhamento em tempo real dos resultados da implementação das decisões adotadas, a retroalimentação da tomada de decisão dos gabinetes e a análise dos impactos sociais das decisões econômicas deve compor um conjunto de ações estratégicas para o reposicionamento organizacional da política social na gestão governamental, para a integração operacional das diversas áreas sociais e para a melhoria da coordenação estatal de suas intervenções 4 .

A intensificação da construção de uma infraestrutura deinformação nasúltimas décadas, que espalhou plataformas de computação/comunicação mundo afora, culminando nas redes interativas, tanto quanto as recorrentes promessas de aumento ou diversificação da relação Estado/ Sociedade pelos meios contemporâneos de interação eletrônica, especialmente a internet, transformaram o uso das tecnologias de informação e comunicação em verdadeira panacéia para o robustecimento de práticas democráticas nas relações entre instituições governamentais e diferentes comunidades, nacionais e internacionais (reais e virtuais), e entre governos e cidadãos $s^{5,1,6,7,8}$.

Assim, a associação entre informação, tecnologia e política vem sendo abordada a partir de diferentes perspectivas: como requisito para aliviar o déficit estrutural e funcional do sistema político, como condição para a eficiência e democratização da gestão governamental, como recurso de "empoderamento" da sociedadecivil e como meio para reduzir distâncias entre nações mais e menos desenvolvidas, entre outras aproximações não menos importantes, como já mencionado.
Os estudos têm apontado, porém, que disponibilizar informação e tecnologia não é suficiente para a produção de transformações sociais capazes de gerar mudanças políticas. A informação deve poder ser usada e para isto deve ser relevante eacessível. Além disso, deve fazer sentido para os diferentes atores e funcionar como um efetivo recurso democrático nos processos de negociação e decisão sobre políticas públicas. Neste contexto, a comunicação ganha lugar de destaque nos esforços de estabelecer encontros efetivos entre interlocutores diferentes, de forma a afetá- los e mobilizá-los para ações formuladas no meio virtual efísico $0^{9,10,11 .}$

Sem querer esgotar esta ampla problemática, vale destacar nestes estudos uma importante vertente deanálises críticas que, a partir de avaliações sobre experiências em andamento, procuram: identificar os limites e possibilidades destas inovações, examinar ideais institucionais e administrativos que devem anteceder e dirigir os novos meios oferecidos pela tecnologia, analisar novas formas de pensar a comunicação (comunicação participativa, comunicação crítica) e problematizar o uso da informação e tecnologia em processos de construção compartilhada do conhecimento orientadosà reciprocidadeentre saber tecnocientífico, senso comum e saber popular 8, 5, 12 .

N este campo de reflexões, gostaríamos de problematizar as relações entre gestão governamental, produção científica esociedadeem experiências deinteração virtual, explorando algumas questões que a prática de gestão do Projeto Descentralização On Line vem suscitando para pesquisa, para o quefaremos inicialmente a contextualização e descrição do projeto.

\section{O projeto Descentralização On Line}

0 processo de descentralização da gestão estatal da saúde no Brasil logrou instituir nos anos 90 uma arena de concertação federativa na direção nacional do Sistema Ú nico de Saúde - a Comissão Intergestores Tripartite (CIT) - de extrema relevância para as relações políticas entre os governos federal, estaduais e municipais, na condução da reforma setorial desencadeada pela Constituição da República Federativa do Brasil de 1988.

N esta Comissão, que se reúne rotineiramentedesde 1993 no M inistério da Saúde, vêm sendo discutidas e negociadas, por representantes dos gestores governamentais setoriais dos três níveis de governo, as principais estratégias nacionais 
para a operacionalização da gestão descentralizada do SUS no conjunto das unidades políticoadministrativas da Federação Brasileira.

Com a legitimidade política que adquiriu ea experiência acumulada em mais de uma década de funcionamento regular, a CIT vem ampliando seu potencial de contribuir para a atual ização dos conteúdos e formas de regulação sanitária no país, para a integração nacional, regional e sub-regional da federação brasileira e para uma distribuição dos recursos públicos federais mais democrática e mais eqüitativa entre as unidades federativas.

O projeto Descentralização On Line (DOL) foi criado em 1999, no Departamento de Ciências Sociais da Escola Nacional de Saúde Pública da Fundação Oswaldo Cruz (DCS/ENSP/FIOCRUZ), em parceria com o Departamento de Administração ePlanejamento em Saúde da mesma instituição (DAPS/ENSP/FIOCRUZ) ecom o apoio da extinta Secretaria de Políticas de Saúde do M inistério da Saúde (SPS/MS) que, à época, era responsável pela coordenação das reuniões da Comissão Intergestores Tripartite.

Naquelemomento, já setornara evidenteque - exercício da regulação, coordenação, avaliação e controle social do novo sistema de saúde descentralizado demandava o acompanhamento permanente do processo de formulação e operacionalização das estratégias nacionais pelos atores envolvidos em sua implementação nos três níveis de governo.

O setor contava com algumas iniciativas e publicações relevantes, degrande circulação, que divulgavam os principais temas em debate na gestão setorial, sistematizavam informaç̧ões estratégicas e agregavam análises da conjuntura e de experiências concretas, dentre os quais, destacavam-se o site Conferência Nacional de Saúde On Line, coordenado pelo Conselho Nacional de Saúde, o site do M inistério da Saúde, que destinava um link específico para informações sobre a descentralização, e o jornal do Conselho Nacional de Secretários Municipais de SaúdeCONASEM S, de distribuição nacional.

A efetivação das mudanças políticas, institucionais, gerenciais e administrativas exigia não apenas a atualização permanente das informações governamentais, como principalmente a produção de conhecimentos e inovações sensíveis à heterogeneidade das situações locais e regionais do país, e capazes de alimentar o desenho de diferentes alternativas para a reorganização do cuidado à saúde no território nacional.

A proposta do DOL partia do pressuposto de que o compartilhamento de conhecimentos entre profissionais das áreas executivas governamentais, que operam o cotidiano do Sistema Ú nico de Saúde, e profissionais da comunidade acadêmica, isto é, professores e pesquisadores de instituições de ensino e pesquisa, em muito contribuiria para o desenvolvimento de análises e propostas que alimentassem a tomada de decisão setorial, contribuíssem para a qualificação da gestão descentralizada do SUS, e, conseqüentemente, para a maior eficiência eeficácia de suas intervenções.

Assim, o D OL foi desenvolvido visando estabelecer um novo e mais ágil canal de comunicação para a troca de informações e análises sobre a descentralização setorial, por meio da criação de um site $^{13}$ na internet, sediado na Escola N acional de Saúde Pública. Orientado a promover uma comunidade dialógica no território nacional composta por profissionais das áreas acadê micas eexecutivas do SUS, aberta a outros atores sociais interessados em influir na gestão da política de saúde, o projeto objetiva facilitar o acesso público à agenda política da Comissão Intergestores Tripartitee, si multaneamente, veicular opiniões, informações e análises desse público alvo, a partir de um espaço virtual de discussão.

Em seu site na internet, disponibiliza: i) o registro temático das reuniões mensais da CIT; ii) os documentos distribuídos nas reuniões (quando divulgados em meio eletrônico); iii) o Fórum Descentralizar - no qual os visitantes do site podem manifestar-se sobretemas que o projeto elege para debate; e iv) um sistema de busca dos diferentes temas abordados no conjunto das reuniões armazenadas desdemaio de 2000, segundo a seguinte classificação: planejamento e reorganização setorial (regionalização da assistência, controle e avaliação de sistemas e serviços, sistemas de informação e recursos humanos); financiamento e gestão financeira do sistema de saúde; epidemiologia e controle de doenças, vigilância sanitária, atenção básica (Programa Saúde da Família e PACS); assistência ambulatorial e hospitalar; saúde indígena e saneamento.

Além disso, indica outros sites da Internet (links) de interesse para o acompanhamento da gestão do Sistema Ú nico de Saúde e das portarias ministeriais publicadas, para o conhecimento de diferentes iniciativas de observatórios, para o acesso mais rápido a instituições de ensino e pesquisa e a agências de fomento à pesquisa, entre outros.

0 registro das reuniões da $\mathrm{CIT}$ estrutura-sea partir de uma breve apresentação do conteúdo 
temático de cada item da pauta, seguido da sistematização dos argumentos técnicos e políticos apresentados pelos representantes das três esferas de governo durante 0 debate que antecede a tomada de decisão, identificando, por fim, 0 encaminhamento decidido pela Comissão.

A eleição do tema a ser apresentado para debate no Fórum Descentralizar combina os critérios de relevância para a política nacional de saúde, prioridade para o momento de implementação do SUS, falta de consenso entre oS gestores e dimensão técnica relevante. As contribuições dos partici pantes são sistematizadas/ sintetizadas pelo projeto, para encaminhamento formal, em meio impresso, aos representantes da Comissão Intergestores Tripartite, ficando igualmente armazenadas no site e disponíveis para consultas posteriores.

No período compreendido entre os anos de 2000 e2006, o projeto funcionou com uma equipe de no máximo quatro profissionais, especialistas em saúde pública (entreos quaisum jornalista), incluindo a coordenadora, com o apoio eventual de um web designer.

Desde 2002, o DO L integra o campo de iniciativas da Escola de Governo em Saúde da ENSP/ FIOCRUZ e conta com o apoio da Secretaria Executiva do M inistério da Saúde em sua implementação, atualmente através do Departamento deApoio à Descentralização (DAD/SE/M S). M ais recentemente, vem constituindo parceria com 0 Centro de Informação Científica e Tecnológica da Fundação Oswaldo Cruz (CICT/FIOCRUZ) para a indexação do conteúdo do site.

N estes seis anos, a implementação do projeto evidenciou algumas dificuldades para o desenvolvimento e sustentabilidade de iniciativas desta natureza, muitas das quais referidas nas análises da bibliografia revisada:

a) a literatura científica que aborda as interrelações entre informação, tecnologia e comunicação em experiênciasinovadoras degoverno eletrônico, democracia eletrônica, governo baseado em evidências, ou de pesquisa científica de suporte à ação governamental, articula inúmeros campos disciplinares na produção de interfaces de conhecimento de difícil apropriação e socialização, com caráter ainda bastante exploratório;

b) as instituições públicas ainda não dispõem de recursos financeiros e humanos estáveis para o suporte necessário à manutenção e atual ização deiniciativas como essa, especial menteno que se refere ao equacionamento de problemas operacionais na gestão de sites na internet;

c) a gestão de projetos desta natureza e a exe- cução de suas atividades exigem equipe multidisciplinar, composta por profissionais de formação disciplinar sólida e capacidade de dialogar com campos muito distintos de conhecimento, para 0 alcance de seus objetivos e a qualidade de seus resultados;

d) o público que recorre a este tipo de inovação atua predominantemente como visitante e usuário, receptor da informação, raramente participando ativamente na emissão de informação ou no compartilhamento de conhecimento.

Estas dificuldades, defato, freqüentementese apresentam como limites importantes para a consolidação de projetos que buscam articular gestão governamental, informação e tecnologia, restringindo sua capacidade de contribuir para o fortal ecimento de práticas de planejamento eavaliação participativos, para o maior controle político sobre o investimento social, para 0 alargamento dos âmbitos de discussão pública, enfim, para a democratização da informação de valor político.

No entanto, não impedem que no âmbito de sua execução venha se avançando na melhor delimitação do campo teórico-metodológico dereferência para estas inovações, no desenvolvimento de novas perspectivas de aproximação à realidade social e à gestão governamental e na compreensão de suas possibilidades e limites.

O conhecimento da política de saúde alcançado pela equipe na implementação do projeto Descentralização On Line, a ampliação e democratização do acesso a informações estratégicas nacionais e locais, constatada no acompanhamento das reuniões mensais da CIT, e a qualidade técnica das participações obtidas no Fórum Descentralizar, permite-nos afirmar que a introdução de novos instrumentos que contribuam para a maior transparência da gestão governamental e coloquem em comunicação diferentes perspectivas da realidade sanitária pode promover um expressivo salto de qualidade no debate público e representar uma fonte de alternativas para correções de rumo na implementação de estratégias nacionais.

Por outro lado, uma análise preliminar do conteúdo do site, realizada pela equipe do projeto, permite afirmar que o material ali armazenado representa uma boa fonte para a identificação detendências do padrão de intervenção estatal setorial em diferentes conjunturas governamentais, para o melhor entendimento da agenda e do modus operandi da direção nacional do SUS na produção de políticas públicas e para o mapeamento das principais divergências entre os 
gestores governamentais das três esferas de governo no processo de operacionalização da gestão descentralizada.

Assim, isolados os limites operacionais, o grande limite da experiência do $D O L$ relacionase ao estabelecimento da interatividade pretendida para o desenvolvimento de análise e proposições quealimentem o processo decisório. A pesar do site registrar 21.000 acessos durante sua existência, as atividades constitutivas do projeto não foram suficientes para estimular a interlocução entre atores de inserção acadêmica e de inserção governamental, com interesse comum na qualificação da gestão descentralizada do SUS.

0 momento atual do Descentralização On Line é de aval iação de seus objetivos e de suas atividades. A revisão bibliográfica realizada com este propósito evidenciou que é preciso ir muito al ém da ampliação do acesso eletrônico a informações de interesse coletivo e da criação de espaços virtuais de participação social para a geração de novos espaços públicos politicamente produtivos.

N esta revisão, duas questões se destacaram para o exame de alternativas que visem potenciar o núcleo positivo de experiências de interatividadeentregoverno, produção científica esociedade, que, a nosso ver, contribuem para a melhor delimitação equalificação de projetos desta natureza.

\section{Gestão governamental, produção científica e sociedade em experiências de interação virtual}

A primeira questão diz respeito aos limites epossibilidades para que experiências de interação virtual que articulem gestão governamental, produção científica e sociedade contribuam para a transparência das informações e das ações governamentais. 0 tema já é bastante complexo, sem que se considere a mediação da produção científica nesta relação.

Santos ${ }^{5}$, em seu abrangente e minucioso estudo sobre o que deve e o que não deve fazer um governo eletrônico, ressalta, segundo Cardoso et al. ${ }^{14}$, que na construção de iniciativas governamentais voltadas para a transparência informacional é preciso se ter clareza quanto às distintas formas e capacidades da sociedade civil de formular demandas ao Estado. A distância que separa os diferentes grupos sociais do acesso ao aparato burocrático pode variar muito, até o limite daqueles que sequer se reconhecem como portadores de direitos e, portanto, legítimos de- mandantes de informação governamental acessível a suas realidades e necessidades.

0 autor afirma que, a depender do uso que se faça da informação governamental e do grau alcançado de regulação sobre ela em cada sociedade, 0 arsenal tecnológico podefacilitar ou obstruir o aumento de interatividade entre os usuários ou um diálogo autêntico entreeles. A "opacidade informacional" pode ser ativada como um "estratagema de poder", instituindo, por meio da gestão da informação, uma "transparência informacional" diferenciada ou restrita a setores e grupos sociais com penetração política e administrativa privilegiada - o que reproduziria assimetrias importantes. Assim, Santos ${ }^{5}$ assinala a necessidade de cautela quanto às promessas, da sociedade da informação e da disseminação das políticas degoverno eletrônico, de favorecer utopias universalizantes.

Encontramos perspectiva diferenteem Guendel $^{1}$. 0 autor, ao analisar os desafios para 0 desenvolvimento de uma gestão do social fundada no enfoque dos direitos humanos, destaca os temas da informação e da comunicação como estratégicos para um planejamento social democrático e ético. À informação, quando vinculada ao alargamento dos âmbitos de discussão pública, é atribuído grande valor na busca de um sistema político e social inclusivo e sustentado por uma atuação reflexiva das pessoas. A comunicação, por sua vez, representa recurso fundamental para a construção de um discurso com sentido, quefacilite reconhecimento recíproco entre os diferentes interlocutores e gere identidades necessárias à articulação de aç̃̃es sociais.

0 autor ressalta a urgência e a importância de se investir em estratégias, sistemas e metodologias que, apoiados na concepção de participação cidadã como essência da gestão, assegurem transparência ao processo de intervenção social, permitindo, assim, o efetivo acompanhamento da configuração de uma política, desde o seu desenho, passando pelo seguimento aos programas e projetos atéa avaliação técnica esocial dos resultados.

A identificação do problema em sua origem, a partir do conhecimento adequado do entorno e das necessidades sociais objetivas, e o desvendamento defacetas da diversidadesocial não val orizadas nos paradigmas vigentes resultariam em um maior impacto social das intervenções e no redimensionando da realidadesocial sobrea qual se quer intervir. Esta nova ética política, fundamentada em nova racionalidade técnica, impulsionaria mudanças normativas e culturais na ope- 
racionalização de uma nova institucionalidade pública, ao tempo em que promoveria processos de mobilização social orientados a uma mudança cultural com enfoque institucional.

Informação, comunicação e mobilização social constituiriam, pois, a tríadeinstrumental de que disporia - o que o autor denomina - "la nueva gerencia social con enfoque de derechos" para propiciar os acordos políticos, transmitir e massificar as novas tecnologias deintervenção social e gerar uma cultura política baseada em compromissos reflexivos em todos os níveis, desde o cotidiano, passando pelos acordos burocráticos e os grandes acordos políticos derivados das macropolíticas públicas.

De acordo com este enfoque, a transformação dos fatos da vida cotidiana e institucional em objeto de discussão pública, e dos dados em fatos sociais, motivariam uma discussão argumentativa e favoreceriam a emergência de regras coletivas e democráticas nos processos de tomada de decisão públicos. As decisões públicas basearse-iam em ações acordadas entre Estado, sociedade civil e comunidade. Além disso, a transparência do processo de intervenção governamental, por meio da produção de informações pertinentes, si stemáticas e fundamentadas cientificamente, propiciaria o empoderamento social e modificação das práticas e valores sociais.

A questão é igualmente tratada por $\mathrm{Grau}^{11}$, em artigo que aborda a transparência como vaIor político na agenda internacional. A autora, além de enfatizar a importância da transparência das informações governamentais para a compensação das assimetrias de poder existentes nos espaços de formação de decisões públicas e 0 impacto que experiências bem-sucedidas podem ter sobre 0 aumento da eficiência, examina os atributos da informação e os meios necessários para viabilizá-la. Assumindo como pressuposto que a administração pública tem uma influência direta na construção da cidadania, e, portanto, efeitos chave na sociedade, desenvolve a tese de que a transparência informacional, mais do que conter abusos de poder e corrupção, pode ser um poderoso instrumento de mudança política em prol de uma gestão mais democrática e eficiente.

Dentre os aspectos analisados - leis de acesso à informação, canais institucionais e políticas de informação, faz uma breve, porém relevante, referência à necessidade de tradução da informação governamental em linguagem acessível ao público não especializado, para que esta possa ser efetivamenteincorporada à participação cívica. Segundo Grau ${ }^{11}$, o acesso livre à informação pública, além de facilitar o conhecimento da sociedade sobre as razões das decisões públicas, contribui para que agências da cidadania, com as competências técnicas necessárias, traduzam a informação especializada de modo a permitir sua apropriação no exercício da cidadania. Estes objetivos já podem ser encontrados em iniciativas de organizações sociais, observatórios de cidadãos, ongs e movimentos sociais em vários países da América Latina (Argentina, Brasil, Colômbia, M éxico).

Assim, parece lítico afirmar, mesmo adotando a posição de cautela sugerida por Santos ${ }^{5}$, que projetos queintroduzam novos canais decirculação de informações entre gestão estatal esociedade, utilizando as novas tecnologias da "sociedade da informação", podem contribuir para a ampliação da transparência da ação governamental, na direção de ideais democráticos e eqüitativos.

Do que foi exposto, é possível elencar alguns eixos de ação que, se combinados, podem sustentar o êxito de iniciativas de interação virtual nessa direção, tais como: i) o controle público sobre a regulação da produção, do uso e da disseminação da informação, de um lado, esobre o acesso ao arsenal tecnológico, de outro; ii) o investimento na ampla divulgação das informações que circulam nos espaços virtuais e presenciais de discussão pública em veículos de comunicação de máximo alcance social; iii) o desenvolvimento pela sociedade civil de atividades de mobilização social nos territórios local, regional e nacional, que reúnam atores com participação política nestes diferentes ambientes e iv) 0 encontro de um "campo de interseção" entre as retóricas e linguagens dos distintos segmentos sociais em interação, em que o preconceito mútuo dêlugar a um processo construtivo de comunicação entre diferentes.

No entanto, há que se considerar, como alerta a literatura, que os desafios são muitos e a proliferação de meios eletrônicos de acesso à informação pública com a finalidade de dar maior transparência à gestão governamental não assegura necessariamentemais democracia, mais eficiência ou mais abertura da gestão governamental às contribuições da sociedade.

U ma dimensão de desafios não suficientemente analisada que pode comprometer, a nosso ver, o impacto destas inovações na qualificação e democratização do processo decisório, na perspectiva de análise aqui desenvolvida, referese à conjugação da informação técnica especializada - que apóia a gestão - com as informações oriundas do saber dos diferentes sujeitos 
sociais - que movimentam os serviços, a política ou pressionam pelo respeito aos direitos sociais - na tomada de decisão governamental.

0 grande desafio que se apresenta é o de encontrar mediações produtivas entre as formas de conhecimento dos diferentes atores, de modo a estabelecer um "ponto de equilíbrio" na comunicação entre gestores governamentais e sociedade para o redimensionamento e enfrentamento de problemas concretos. E isto não se reduz a traduzir conhecimento técnico-científico em linguagem simples. $\mathrm{Nem}$ a simplificar a complexidade do conhecimento requerido pela gestão. M as, como sugere Barros $^{10}$, significa garantir a pluralidade de visões sobre a realidade social e valorizar 0 olhar político sobre a gestão governamental.

Isto nos remete à segunda questão que gostaríamos de explorar: de que maneira a produção científica pode contribuir para veicular essa pluralidade de visões e promover o olhar político sobre a gestão governamental?

Em várias partes do mundo, a ciência, em especial as ciências sociais, vem sendo convocada a dar sua contribuição na produção de análises independentes da ação dos governos; na avaliação da qualidade das evidências que embasam as políticas governamentais, no questionamento às explicações oficiais sobre os problemas sociais; no desenvolvimento deinvestigações empíricas rigorosas para a produção de novas evidências e na democratização do conhecimento e na responsabilização dos governos por suas escolhas e ações. Particularmenteem países da América Latina, Ásia e África, é crescente a demanda de organizações governamentais e não-governamentais pela expertise dos cientistas sociais ${ }^{15,16,16}$.

N esta interação, freqüentemente os pesquisadores são criticados por sua linguagem opaca, impenetrável e inacessível a policy makers e ao público não especializado em geral, e pela falta de destreza na comunicação com aquel es que estão buscando encontrar soluções para os problemas que pressionam o desenvolvimento estratégico e político. Em decorrência disso, espera-sedos pesquisadoresque desenvolvam uma linguagem acessível e formas de apresentação de sua produção amigáveis e de fácil e rápida apropriação.

Por outro lado, também é crescente o reconhecimento nas sociedades democráticas contemporâneas de que, para o efetivo atendimento às necessidades sociais, não se pode prescindir do diálogo entre tecnociência e senso comum. No Brasil, particularmente no setor saúde, no campo de práticas da educação em saúde, já vem se desenvolvendo, inclusive, novas formas de articular esses saberes, denominadas pelos atores sociais processos de construção compartilhada do conhecimento ${ }^{18,12}$.

Para a assunção destas tarefas, há que se contar com profissionais com formação sólida e abrangente, com múltiplas habilidades e capacidade de tornar os insights do campo científico acessíveis aos policy makers e à sociedade em ge ral. Profissional que, dada a situação deestilhaçamento dos campos disciplinares, de ausência de grandes sínteses de conhecimento, de fragmentação e desarticulação institucional da produção científica, o campo da ciência e tecnologia não está conseguindo formar. E as mudanças necessárias para estabelecer essa formação não se farão no curto prazo. Não obstante, vale mencionar, não é incomum encontrar esse perfil entre profissionais em exercício na gestão governamental.

Assim, parece lícito afirmar que experiências de interação virtual entre governantes e sociedade, que contemplem mediações entre formas de conhecimento e visões da realidade de diferentes atores sociais e evidenciem quea gestão das políticas públicas, mais do que de um conjunto de análises técnicas, deriva de escol has políticas informadas por visões de futuro e de impactos sociais, podem ter uma importante função a cumprir neste momento de renovação do ethos da comunidadecientífica. 


\section{Colaboradores}

P Ribeiro, DC Sophia e DA Grigório participaram igualmente de todas as etapas da elaboração do artigo.

\section{Referências}

1. Guendel L. Por una gerencia social con enfoque de derechos. IIG; [ 200-] [documento na Internet]. [acessado 2003 Set 17]; [cerca de 13 p.]. Disponível em: http://www.iigov.org/documentos/?p=3_0108

2. M oraes MR. As relações intergovernamentais na Re pública Federal da Alemanha: uma análise econômico-institucional. São Paulo: Fundação Konrad Adenauer; 2001.

3. Scharpf FW. No exit from the join decision trap? Can German federalism reform itself? 2005. [cited 2005 Feb 25]. [about 28 p.].Available from: http:// www.mpi-fg-koeln.mpg.de/pu/workpap/wp05-8/ wp05-8.html

4. Kilksberg B. Repensando o estado para o desenvolvimento social: superando dogmas e convencionalismos. (Coleção Questões da Nossa época, v. 64). São Paulo: Cortez; 1998.

5. Santos RJL. Governo eletrônico: o que se deve e o que não se deve fazer. Caracas: [s.n.], 2002. [acessado 2006 M ai 30]. [cerca de 67 p.]. Disponível em: http://www.cnti.gob.ve/cnti_docmgr/sharedfiles/ gobiernoeletronico9.pdf

6. Prats JO, Alamo O. Democracia electrónica: concepto, tipos y posicionamientos. IIG; [200-] [documento na Internet]. [acessado $2006 \mathrm{M}$ ai 28]. [cerca de $17 \mathrm{p.}$.] Disponível em: http://www.iigov.org/documentos/ $? p=6 \quad 0094$

7. Paseta M. Las nuevas tecnologías de la comunicación como herramientas para el desarrollo. Catalunya Global, [periódico na Internet]. 2002 Jul [acessado 2002 Ago 04];(16): [cerca de 8 p.]. Disponível em: http://www.iigov/cpd/biblioteca/cg/cg16/cg16 03

8. Schiavo E, Zanchetti E, Coppolecchio L. Gobierno electrónico y modernización de la administración pública: Caso de estudio: municipio de Pinamar, Argentina. [documento na Internet]. [acessado 2006 Jun 01]. [cerca de 23 p.] Disponível em: http:// www.82.194.71.46/documentos/print.php?print $=6 /$ $6 \_0093 \& T 1=\&$ pagina $=\&$ grupo $=\& d 1=$
9. Pitta AM R. Interrogando os campos da saúde e da comunicação: notas para o debate. In: Pitta AMR. Saúde \& Comunicação: visibilidades e silêncios. São Paulo: ABRASCO; 1995.

10. Barros JC. Aspectos comunicacionais e informacionais nas novas relações entre sociedade civil e poder público: o caso dos conselhos deliberativos de políticas públicas. Perspec Ciênc Inf 2003; (8):58-71.

11. Grau NC. La transparencia en la gestión pública: ¿Cómo construir viabilidad? In: Mezones F, organizador. Transparencia en la gestión pública: ideas y experiencias para su viabilidad. Guatemala: BID, Instituto Interamericano para el Desarrollo Social, Instituto Nacional de Administración Pública de Guatemala, Real Ministerio de Asuntos Exteriores de N oruega; 2006.

12. Araújo JW. Ciência e senso comum: a divulgação do conhecimento no campo da saúde. Perspec $\mathrm{Ci}$ ênc Inf 2003; (8):72-93.

13. http://www.ensp.fiocruz.br/descentralizar.

14. Cardoso AMP, Bemfica JC, Reis AS. Entre a imagem e a ação: a produção de informação governamental para gestão de políticas de assistência social. Inform Publ 2000; 2(1):67-79.

15. Lauder H, Brown P, Halsey AH. Sociology and political arithmetic: some principles of a new policy science. Br J Sociology 2004; 55:4-22.

16. Davies $P$. Is evidence-based government possible? In: $4^{\text {th }}$ Annual Campbell Collaboration Colloquium; 2004 Feb. 19; Washington, D.C.

17. Quah SR. Four sociologies, multiple roles. $\mathrm{Br}$ J Sociology 2005; 56:395-400.

18. Valla VV, Marteleto RM. Informação e educação popular: o conhecimento social no campo da saúde. Perspect Ciênc Inf 2003; 8.

Artigo apresentado em 29/06/2006

Aprovado em 29/08/2006

Versão final apresentada em 05/10/2006 